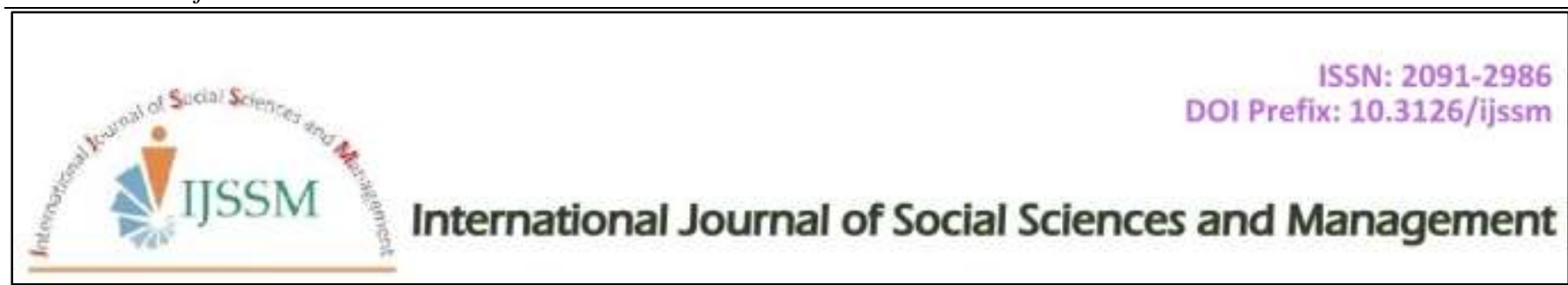

Research Article

\title{
Coping Strategies of Nursing Student against Academic and Clinical Stress at Public Sector Lahore
}

\author{
Samina Yasmin ${ }^{1 *}$, Muhammad Hussain ${ }^{1}$, Kousar Parveen ${ }^{1}$, Syed Amir Gilani ${ }^{1}$ \\ ${ }^{1}$ Lahore School of Nursing, The University of Lahore, Pakistan
}

\begin{abstract}
Nursing is an emotionally demanding and a highly stressful profession as nurses has to deal with different people, in various situations and different times of the day. During their everyday work, they have to cope with extremely emotionally charged and rapidly changing circumstances. It is a universally accepted fact that human nature is prone to wears and tears associated with daily activities. These manifest in the form of stress and strains as witnessed in everyday life. Nurses and other healthcare professionals are exposed on daily basis to different levels of stress and burnout arising from the demand for their jobs. To explore the coping strategies of nursing student against clinical and academic stress. A quantitative, descriptive cross-sectional study design was used to explore coping strategies of nursing students against academic and clinical stress at public hospital Lahore. The instrument use for the data collection was adopted questioner and convenient sampling technique was used. The mean difference is significant at the 0.05 level. It is observed that academic and clinical stress sources and coping mechanisms are statistically significant, as p-value $<0.05$. The present study was considered as a cornerstone that gives strong support towards coping strategies of nursing student against academic and clinical stress. It highlighted there are number of clinical and academic stress that hinder good performance of student. These results substantiate the belief that aspects of the practice environment affect student nurse academic performance and most importantly, the quality of care delivered on clinical placement to the patient.
\end{abstract}

Keywords: Coping Strategies; Clinical Stress; healthcare

\section{Introduction}

Nursing is an emotionally demanding and a highly stressful profession as nurses have to deal with different people, in various situations and different times of the day. During their everyday work, they have to cope with extremely emotionally charged and rapidly changing circumstances (Forouzanfar et al., 2016). However, nursing training is a stressful process. Nursing students face both physical and psychosocial risks such as job stress at work during the training period. Because they have clinical duties related to patient care in clinical environments, they experience clinical stressors (Liu et al., 2015). The sources of stress for nursing students can be assembled as academic, intrapersonal, interpersonal, and environmental. The most common sources of stress are academic workload, fear of unknown situations, mistakes with patients or handling of technical equipment. Not knowing how to communicate with patients, lacking the care skills, stress from peers and daily life restrictive environment are the factor that

\section{Cite this article as:}

S. Yasmin et al. (2018) Int. J. Soc. Sc. Manage. Vol. 5, Issue-3: 209-218. DOI: 10.3126/ijssm.v5i3.20613

$1 *$ Corresponding author

Samina Yasmin,

Lahore School of Nursing, The University of Lahore, Pakistan

Email: saminayasmin727@gmail.com

Peer reviewed under authority of IJSSM

(C) 2018 International Journal of Social Sciences and Management

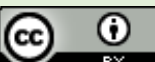

This is an open access article \& it is licensed under a Creative Commons Attribution 4.0 International License (https://creativecommons.org/licenses/by/4.0/) 
influence on nursing student (Bryan et al., 2016). Moreover the other factor leading to stress are lack of quality free time, difficulty in time management, and inconsistent faculty responses to their concerns gap between theory and practice, and lack of clinical supervision (Van Eylen et al., 2014). The most common type of stress nursing student faced is academic or clinical stress. Academic stress means education related stresses. Academic stress is the main sources of stress faced by nursing student. The factor leading to academic stress are preparation for exams, receiving negative feedback from teachers in the clinical environment, passing theoretical exams or assessments, dissatisfied with instructional methods, uncertainty about content and curriculum, gaps between theory and practice and lack of guidance from teachers (Akhu-Zaheya, Shaban, $\&$ Khater, 2015). Moreover other academic stress factor such as poor communication among teacher and nursing student and lack of support in their study was viewed as crucial and expected to increase the feelings of frustration and dissatisfaction among nursing students (Blomberg et al., 2014). In another study, the factor which cause academic stress faced by nursing students are examination and the timing of examinations, student spend most of their time in preparation for examination that disturb work-life balance of nursing students. They also experience longer hours of study and an associated lack of free time. Moreover, poor classroom set up is also a sources of stress for student that does not promote a positive learning environment (Hawker, 2012). Nursing student also faced different stresses at clinical site. Clinical stress means workplace or clinical site related stresses among nursing student. Clinical stress is the second main sources of stress faced by nursing student. Factor leading to clinical stress are fear of making a mistake in clinical placements and feeling responsible for what happened to patients, not having enough time to fulfill all functions of nursing and how to discuss patients' illness with clinical instructor are common stressors perceived by nursing students (Malig, Pearson et al. 2016). Moreover other factor leading to clinical stress are communication errors among nurses' student and clinical instructor and negative feedbacks given by clinical instructor at their clinical placement in front of patients (Bryan et al., 2016). Other additional factor of clinical stress are such as working with dying patients, conflicts with other staff, insecurity about clinical competence, interpersonal problems with patients, and work overload. Not knowing how to help patients with emotional problems, not sharing of emotions and experiences related to clinical practices with nursing staff (Torres et al., 2015). Consequently, other factor of clinical stress were a lack of caring attitudes of instructors with their student while nursing student are caring of a patients that negatively affects their motivation to learn, not developing clinical skills and perceived a lack of practical skills. Time pressures was also a factor of stress within which they are expected to work on clinical placement (Knutson et al., 2014). Nurses need to cope with stress through coping strategies. Coping strategies are key elements of nurses' stress reactions. Coping strategy are a stabilizing factor that are as important as the stressful event itself. Nursing students' stress in their clinical and academic placement can be altered by the coping strategies they choose to apply. Effective coping strategies help students to perform markedly better in regards to their studies; coping strategies also aid in relieving students' stress. Several researchers found that the best and most useful coping strategies are problem solving, transference (efforts to keep a positive attitude toward the stressful situation), and unrelenting optimism (Bryan et al., 2016). The other coping strategies mostly used by nursing student at their academic and clinical placement are self-confident approach, optimistic approach, and social support seeking approach focused on reducing stressors (Huber et al., 2013). Additionally, other coping strategies nursing students generally used are problem solving coping strategies including optimistic action and social support to deal with the entrance exam stress, but use of emotion-focused coping strategies including avoidance. Problem-focused coping had a positive main effect of reducing psychological distress (Bryan et al., 2016). In another study, nursing student cope with academic and clinical stress by removing the stressor through manipulating the environment, developing specific responses to help cope with the stressor or seeking diversion from the stressor (Akhu-Zaheya et al., 2015).

\section{Problem Statement}

It is a universally accepted fact that human nature is prone to wears and tears associated with daily activities. These manifest in the form of stress and strains as witnessed in everyday life. Nurses and other healthcare professionals are exposed on daily basis to different levels of stress and burnout arising from the demand for their jobs. Nurses play a key role in the efficient health care services. However, academic and clinical stress elements may create the issues for the nurses and affect the services. In Pakistan, nurses have high stress level which minimize the quality of patient care and ultimately hospital practices will be compromised. Therefore, it is need of the time to investigate the source of stress among nurses and their coping mechanisms at a workplace, so that the solution to the problem can be provided and the quality of healthcare services are not compromised (Sikander \& Aziz, 2012). Stress has been recognized as serious health problem among nurses. It declines the quality of work performance and standard of living. Majority of nurses have severe stress level in everyday life which may put negative effects on their health and professional responsibilities (Badil et al., 2016). It has been found that one in five nurses want to quit their job and $40 \%$ nurses experience considerable burnout due to academic and workplace stress. Consequently, burnout is 
the leading cause of stress among nurses (Roberts \& Grubb1, 2014).

\section{Significance of the Study}

The quality of education and patient care is revealed by good performance of nursing students during the academic and training period. Current study will be a source of information for improving my knowledge regarding source of stress that nursing student faced at their academic and clinical site. This study will motivate and enhance the learning attitude of nursing students within class room and clinical placement. The results of this study may benefit the students by allowing them to understand the factors that affect their academic and clinical learning in better way. Students become able to used different coping strategies to face different stressors. The findings of this study will help the nursing college and hospital administration to implement the policies to eradicate the factors that cause stress among nursing student at academic and clinical site. This enables the students to utilized better coping strategies of stress which produce quality nurses and their performance at clinical site will be improved. These efforts help the nurses to become competent health care professional to give high quality patient care and hospital prestige will be enhanced.

\section{Purpose of Study}

The purpose of this study is to explore coping strategies of nursing student against academic and clinical stress at public hospital Lahore.

\section{Research Question}

1) What are the stressors that cause academic stress among nursing student?

2) What are the stressors that cause clinical stress among nursing student?

3) What is the relationship between academic and clinical stressor that cause stress?

4) What are the coping strategies nursing students used to cope with clinical and academic stress?

\section{Objective of Study}

1) To explore the stressors that cause academic stress among nursing student

2) To explore the stressors that cause clinical stress among nursing student.

3) To find relationship between academic and clinical stressor that cause stress

4) To determine the coping strategies nursing students used to cope with clinical and academic stress.

\section{Theoretical Framework}

The theoretical framework used for this study is the Transactional Model of Stress and Coping by Lazarus and Folkman (1984). The Transactional Model of Stress and Coping is a framework for evaluating the processes of coping with stressful events. This Model is applicable to the current study because Student Nurses are usually faced with enormous responsibility and demands for care, the intense emotional pressure surrounding death and dying, prolonged and exhausting working hours. Transactional model Emphasis on how stress affects their behavior and output as it relates to the quality of care they are capable of rendering and how to overcome stress (Lazarus \& Folkman, 1984).

\section{Literature Review}

Stress is a global phenomenon and has been found to have bad health impact and adversely affect the learning of students, it is difficult to avoid from stress in daily living. Nursing student have various causes of clinical stress, including long duration of working hours, heavy work load, night shifts resulting in sleep deprivation, imbalance between work and life, isolated feelings, and loss of control over the workplace stress, presented by less autonomy and cause of stress (Furukawa et al., 2017). The most commonly stated academic stressor were assignment workload whereas the commonly reported clinical stressors were lack of knowledge, inadequate training, and long hours of duties at clinical placement that affect the emotional and behavioral health and social life of the Nursing student (Sikander \& Aziz ,2012). According to Sharif (2015) the most important academic source of stress among nursing student are to the preparation of examination, not availability of resources on illness in Nursing library and dis-satisfied with instructional method which are not only compromise the delivery of patient care, also affect the health and clinical practice of nursing students. However, the most commonly occurred clinical stress among nursing student is to being criticized by teachers in clinical environments. According to Jung \& Park (2015) study on academic stressors showed that the important source of stress was being receiving negative feedback from teachers in the academic placement and uncertainty about content and of curriculum. This causes feeling of frustration and distress among nursing student. According to author found that clinical stress caused by over work load at clinical site and Nursing student have not enough time to fulfill the function of nursing that interrupting learning among nursing students in a clinical learning environment of stress among nursing student (Furukawa et al., 2017). According to Shukla (2013) clinical sources of stress includes fear of the unknown clinical environment, conflict between the real and ideal clinical practice, lack of professional nursing skills, unfamiliar patients' diagnoses and treatments, providing physical, psychological and social care to patients, fear of making mistakes, and the death of a patient . In another study observed that nursing students are being stressed during academic site. Nursing students are suffered with many issues that hinder student's capabilities. The most observed sources of stress are fear of failure, uncertainty about future, lack of confidence, unease 
anxiety, sadness, depression, lack of self-confidence negative attitudes, short temper, poor sleep and poor satisfaction about performance indicator defined as marker which gives incitement towards stress which causes feeling of distress, anxiety and depression (Papathanasiou et al., 2014). Several researchers found that the most common source of stress at clinical placement among nurses were being criticized by teachers in the clinical placement, followed by encountering a dying patient and the fear of making practice errors (Bryan et al., 2016). A study showed that major sources of clinical stresses for nurses incorporates, workload, workplace environment, conflict between relationship with senior, Lack of staff and high turnover, having excessively work to do, assuming disagreeable clinical practice, independently performing of difficult task and inactive favors, outcomes of committed errors, seek after the vocation to harm of the well-known life, bringing the work at home, insufficient supervision of the bosses, feeling secluded among others (Milsom et al., 2012). Another study showed that nursing students have stresses are mainly related to the rules and regulations of nursing schools, teachers rude behavior, communication error among student and teacher that lead to stress among nursing student which causes feeling of distress and anxiety among student, to cope with these manifestation need to be effective coping strategies by cooperation with members of health teams (Malig et al., 2016). Several study found, that because of academic and clinical stressors, nursing students are distressed, disappointed and experience a lack of motivation and burnout. So it is important to know whether the students use effective coping methods or not. In clinical learning environments, the support and attitudes of clinical instructor is vital for nursing students. The opportunities and encouragement given by clinical instructor increased the confidence level of nursing students in clinical practice (Allan et al., 2016). Another study showed that to manage the stress arising from long working hours, there is need for management action on limiting the amount of hours done by student nurses. Nurse Managers should be arranging the shifts and the duration of shifts to avoid from unnecessary stress. greed that stress is associated to the number of hours done by nursing but added that the availability of social support and time management helped to reduce the negative effect of the stress on their performance (Acikgoz et al., 2016). Consequently, social support was identified as an effective coping strategy for nurses to cope with stress. By this, a better-organized management structure and organized individual working practice are seen as effective way of managing or coping with work stress is in agreement with that coping resource such as social support or working group is an effective coping strategy for coping with stress. Other coping strategies include effective communication strategies, prevention of management conflicts and perceived control (Rinsky et al., 2013). In a study conducted in Jordan, nursing students most frequently used problem solving as a coping strategy, while avoidance was used the least. Similarly, in a Taiwanese study, problem solving and staying optimistic were more frequently used than other coping strategies. The uses of the problem-solving strategies need the individuals to make an active effort and to create solutions, unlike the avoidance strategy (Demir et al., 2014).

\section{Methodology}

Study Design: A quantitative, descriptive cross-sectional study design was used to explore coping strategies of nursing students against academic and clinical stress at public hospital Lahore.

Setting: The setting for this study was the College of Nursing, King Edward Medical University Lahore. Data was collected from nursing students regarding the coping strategies of nursing students against academic and clinical stress at public hospital Lahore.

Study Population: Study Population for this research was the Nursing Students of the College of Nursing, King Edward Medical University Lahore.

Sample Size: The Sample size was194 nursing students.

Sampling Method: To recruit the required sample, a convenient sampling technique was used, which is nonprobability sampling method.

Inclusion Criteria: All female General Nursing Diploma Students $\left(1^{\text {st }}\right.$ year, 2 nd and $3^{\text {rd }}$ year) having age 15 to 30 years from the College of Nursing, King Edward Medical University, Lahore and who are willing to participate was included in this study.

Exclusion Criteria: Midwifery Student and students having age less than 15 years and above 30 years was excluded. Nursing Students who are not interested and not willing to participate was excluded. Male nurses were also excluded in this study.

Study Duration: Study will be conduct in four months Jan 2018 to May 2018.

Data gathering plan: Data was gathered by distributing close-ended questionnaire among nursing students of the College of Nursing, King Edward Medical University Lahore. An adopted questionnaire about the academic and clinical stress resources and way of coping mechanisms is used here. The questionnaire is adopted from published research article (Bahadır-Yılmaz 2016).Study participant was guided and instructed to fill the questionnaire.

Data analyze: Data was be analyzed by using the Statistical Package for the social science (SPSS) 21, descriptive statistics such as frequencies, means, SD- Deviation and percentages. One way ANOVA was used to find relationship between academic and clinical stressor among nursing student. 
Tool of Research: Questionnaire consist on 4 sections, $1^{\text {st }}$ section contain demographic questions, $2^{\text {nd }}$ section contain questions on clinical stress, $3^{\text {rd }}$ section contain questions on academic stress and $4^{\text {th }}$ section contain questions about coping strategies, adopted from published research article questionnaire was used to collect the information (BahadirYilmaz, 2016).

Ethical Consideration: Permission was taken from the Principal Lahore School of Nursing, The University of Lahore. Permission was also taken from College of Nursing, King Edward Medical University Lahore. A consent form will be attached with each questionnaire. The information of respondent was kept confidential. They gave full permission to withdraw at any time if they want.

\section{Data Analysis and Interpretations}

Data analysis and interpretation means to define characteristics of each component in various aspects and measure it mathematically by applying different strategies or test, manipulate the required things by following the statistics rules or principles to determine the relationship between components or variables and that relation is to interpret and examine the finding with aspects (Thompson, 1993).

\section{Demographic Data Analysis}

Table 1 shows that gender of participants, $100 \%(n=194)$ are female nurses from king Edward College of Nursing Lahore. Mean of gender is (2.00+.00)._Among age of participant 194 attendees, there were $23.7 \%(n=46)$ between 15-18 years, $47.9 \%(n=93)$ were between 19-22 years, $28.4 \%(n=55)$ between $23-26$ years $(2.05 \pm 0.722)$. There were $35.6 \%(n=69) 1^{\text {st }}$ year student $32.0 \%(n=62)$ were $2^{\text {nd }}$ year student, $132.5 \%(n=63)$ were $3^{\text {rd }}$ year student in the study with the mean of experience $(1.97 \pm 0.826)$. The figure no 4.5 was related qualification of participants. The data in Table 1 shows that the qualification of participants $45.9 \%$ $(n=89)$ was Matric, 54.1\% $(n=105)$ were Fsc, $0 \%(n=0)$

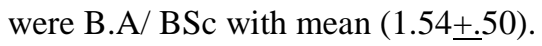

\section{Academic Sources of Stress}

Table 2 shows the data collected from various respondents regarding academic sources of stress. Being not satisfied with instructional methods? $37.6 \%(n=73)$ disagree, $39.2 \%$ $(n=76)$ partially agree, $23.2 \%(n=45)$ participants were fully agree (1.86 \pm .768$)$. Difficulty of finding resources on illness and nursing in library? $19.6 \% \quad(n=38)$ participants were disagree, $40.7 \%(n=79)$ were agree, $39.7 \%(n=77)$ were partially agree with $(2.0 \pm .745)$. Being forced to study continuously for academic success? 34.0\% ( $n=66)$ participants were disagree, $35.6 \% \quad(n=69)$ were agree, $30.4 \% \quad(n=59)$ were partially agree with (1.96 \pm .804$)$. Feelings of time pressure about doing homework? 30.9\% $(n=60)$ participants were disagree, $43.8 \%(n=85)$ were agree, $25.0 \%(n=49)$ were partially agree with $(1.94+.749)$.

\section{Clinical Sources of Stress}

Not accepting teacher's perspective, 24.7\% ( $n=48)$ participants were disagree, $47.4 \% \quad(n=92)$ were agree, $27.8 \%(n=54)$ were partially agree with (2.03 \pm .726$)$, Encountering a dying patient, $26.8 \%(\mathrm{n}=52)$ participants were disagree, $44.3 \%(n=86)$ were agree, $28.9 \% \quad(n=56)$ were partially agree with $(2.02 \pm .748)$ Not having enough time to fulfill all functions of nursing, $25.3 \% \quad(n=49)$ participants were disagree, $47.9 \% \quad(n=93)$ were agree, $26.3 \%(n=51)$ were partially agree with $(2.10 \pm .722)$ Not having enough time to provide emotional support to a patient.26.3\% $(\mathrm{n}=51)$ participants were disagree, $39.2 \%$ $(n=34)$ were agree, $34.5 \%(n=67)$ were partially agree with (2.08+.778) Not talking with nursing staff about problems in clinical practices, $22.7 \% \quad(n=44)$ participants were disagree, $46.9 \%(n=91)$ were agree, $30.4 \%(n=59)$ were partially agree with $(2.08 \pm .726)$. Not sharing of emotions and experiences related to clinical practices with nursing staff?. 28.4\% $(\mathrm{n}=55)$ participants were disagree, $40.7 \%$ $(n=79)$ were agree, $30.9 \%(n=60)$ were partially agree with $(2.03 \pm .771)$. Not knowing how to help patients with emotional problems?, $28.4 \% \quad(n=55)$ participants were disagree, $42.3 \%(n=82)$ were agree, $29.4 \%(n=57)$ were partially agree with $(2.01 \pm .762)$.Uncertainty associated with use of equipment used in patient care. $28.4 \%(n=55)$ participants were disagree, $38.1 \%(n=74)$ were agree, $33.5 \%(n=65)$ were partially agree with $(2.05 \pm .787)$ (Table 3).

Table 1: Demographic Data Analysis

\begin{tabular}{|c|c|c|}
\hline Participants & $\mathrm{n}=194(f) \%$ & \\
\hline Gender of respondents & Female (194) $100 \%$ & \\
\hline Age Group of respondents & $\begin{array}{l}1=15-18(46) 23.7 \% \\
3=23-26(55) 28.4 \%\end{array}$ & $\begin{array}{l}2=19-22(93) 47.9 \% \\
4=27-30(0) 0 \%\end{array}$ \\
\hline Year of study of respondent & $\begin{array}{l}1=1^{\text {st }} \text { year }(80) 41.2 \% \\
3=3^{\text {rd }} \text { year }(20) 10.3 \%\end{array}$ & $2=2^{\text {nd }}$ year $(94) 48.5 \%$ \\
\hline Qualification of respondents & $\begin{array}{l}\text { 1=Matric }(89) 45.9 \% \\
3=\text { B.A/BSc }(0) 0 \%\end{array}$ & $\begin{array}{l}2=\text { FSc }(105) 54.1 \% \\
4=\text { others }(0\end{array}$ \\
\hline
\end{tabular}


Table 2: Academic sources of stress.

\begin{tabular}{|c|c|c|c|c|}
\hline Variable & $\begin{array}{l}\text { Disagree } \\
(f) \%\end{array}$ & $\begin{array}{l}\text { Partially } \\
\text { Agree } \\
(f) \%\end{array}$ & $\begin{array}{l}\text { Fully Agree } \\
(f) \%\end{array}$ & $\begin{array}{l}\text { Mean \& St. } \\
\text { Dv }\end{array}$ \\
\hline Being not satisfied with instructional methods. & $(73) 37.6 \%$ & $(76) 39.2 \%$ & $(45) 23.2 \%$ & $(1.86 \pm .768)$ \\
\hline $\begin{array}{l}\text { Difficulty of finding resources on illness and nursing in } \\
\text { library. }\end{array}$ & (38) $19.6 \%$ & (79)40.7\% & $(77) 39.7 \%$ & $(2.0 \pm .745)$ \\
\hline Being forced to study continuously for academic success. & $(66) 34.0 \%$ & (69)35.6\% & $(59) 30.4 \%$ & $(1.96 \pm .804)$ \\
\hline Feelings of time pressure about doing homework & $(60) 30.9 \%$ & $(85) 43.8 \%$ & $(49) 25.0 \%$ & $(1.94 \pm .749)$ \\
\hline $\begin{array}{l}\text { Receiving negative feedback from teachers in clinical } \\
\text { environment. }\end{array}$ & $(50) 25.8 \%$ & $(89) 45.9 \%$ & $(55) 28.4 \%$ & $(2.03 \pm .737)$ \\
\hline Uncertainty about content and of curriculum & (39) $20.1 \%$ & $(81) 41.8 \%$ & $(74) 38.1 \%$ & $(2.18 \pm .743)$ \\
\hline Inadequately equipped classroom environment & $(50) 25.8 \%$ & (68)35.1\% & (76)39.2\% & $(2.13 \pm .797)$ \\
\hline Preparing for the exam. & (58) $29.9 \%$ & $(71) 36.6 \%$ & $(65) 33.5 \%$ & $(2.04 \pm .797)$ \\
\hline Gap between theory and practice. & $(82) 42.3 \%$ & $(64) 33.0 \%$ & $(48) 24.7 \%$ & $(1.82 \pm .802)$ \\
\hline Intensity of academic workload & $(54) 27.8 \%$ & $(80) 41.2 \%$ & $(60) 30.9 \%$ & $(2.03 \pm .768)$ \\
\hline Home/dormitory environment makes studying difficult. & (39) $20.1 \%$ & $(77) 39.7 \%$ & (78) $40.0 \%$ & $(2.20 \pm .752)$ \\
\hline Passing theoretical exams or assessments & (36) $18.6 \%$ & (73)37.6\% & $(85) 43.8 \%$ & $(2.25 \pm .750)$ \\
\hline Insufficient support from teachers. & (33) $17.0 \%$ & $(89) 45.9 \%$ & $(72) 37.1 \%$ & $(2.20 \pm .710)$ \\
\hline Lack of guidance from teachers. & (48) $24.7 \%$ & $(81) 41.8 \%$ & $(65) 33.5 \%$ & $(2.09 \pm .760)$ \\
\hline Negative feelings about educational achievement. & $(51) 26.3 \%$ & (73)37.6\% & $(70) 36.1 \%$ & $(2.10 \pm .786)$ \\
\hline
\end{tabular}

Table 3: Clinical sources of stress.

\begin{tabular}{|c|c|c|c|c|}
\hline Variable & $\begin{array}{l}\text { Disagree } \\
(f) \%\end{array}$ & $\begin{array}{l}\text { Partially } \\
\text { Agree } \\
(f) \%\end{array}$ & $\begin{array}{l}\text { Fully } \\
\text { Agree } \\
(f) \%\end{array}$ & $\begin{array}{l}\text { Mean \& St. } \\
\text { Dv }\end{array}$ \\
\hline Not accepting teacher's perspective. & $(48) 24.7 \%$ & $(92) 47.4 \%$ & $(54) 27.8 \%$ & $(2.03 \pm .726)$ \\
\hline Encountering a dying patient. & $(52) 526.8 \%$ & $(86) 44.3 \%$ & $(56) 28.9 \%$ & $(2.02 \pm .748)$ \\
\hline Not having enough time to fulfill all functions of nursing. & (49) $25.3 \%$ & (93) $47.9 \%$ & (51)26.3\% & $(2.01 \pm .722)$ \\
\hline $\begin{array}{l}\text { Not having enough time to provide emotional support to a } \\
\text { patient. }\end{array}$ & $(51) 26.3 \%$ & $(34) 39.2 \%$ & $(67) 34.5 \%$ & $(2.08 \pm .778)$ \\
\hline $\begin{array}{l}\text { Not talking with nursing staff about problems in clinical } \\
\text { practices. }\end{array}$ & (44) $22.7 \%$ & $(91) 46.9 \%$ & $(59) 30.4 \%$ & $(2.08 \pm .726)$ \\
\hline Encountering with a patient suffering. & (42) $21.6 \%$ & $(85) 43.8 \%$ & $(67) 34.4 \%$ & $(2.13 \pm .740)$ \\
\hline $\begin{array}{l}\text { Not sharing of emotions and experiences related to clinical } \\
\text { practices with nursing staff. }\end{array}$ & $(55) 28.4 \%$ & (79)40.7\% & $(60) 30.9 \%$ & $(2.03 \pm .771)$ \\
\hline Not knowing how to help patients with emotional problems. & $(55) 28.4 \%$ & $(82) 42.3 \%$ & $(57) 29.4 \%$ & $(2.01 \pm .762)$ \\
\hline Fear of making practice errors. & $(46) 23.7 \%$ & $(91) 46.9 \%$ & $(57) 29.4 \%$ & $(2.06 \pm .728)$ \\
\hline Being criticized by teachers in clinical environments. & $(46) 23.7 \%$ & $(81) 41.8 \%$ & $(67) 34.5 \%$ & $(2.11 \pm .757)$ \\
\hline Not knowing what to say to patient about his/her illness. & (43) $22.2 \%$ & $(82) 42.3 \%$ & (69)35.6\% & $(2.13 \pm .750)$ \\
\hline $\begin{array}{l}\text { Uncertainty associated with use of equipment used in patient } \\
\text { care. }\end{array}$ & $(55) 28.4 \%$ & $(74) 38.1 \%$ & $(65) 33.5 \%$ & $(2.05 \pm .787)$ \\
\hline $\begin{array}{l}\text { Not knowing how to help family of patients about emotional } \\
\text { needs. }\end{array}$ & (39) $20.1 \%$ & (96) $49.5 \%$ & $(59) 30.4 \%$ & $(2.10 \pm .705)$ \\
\hline Giving care for a dying patient. & $(64) 33.0 \%$ & $(88) 45.4 \%$ & $(41) 21.1 \%$ & $(1.88 \pm .730)$ \\
\hline Negative clinical experiences with nursing staff. & $(59) 30.4 \%$ & $(84) 43.3 \%$ & $(51) 26.3 \%$ & $(1.96 \pm .754)$ \\
\hline Having disagreement about patient's condition. & $(60) 30.9 \%$ & $(98) 50.5 \%$ & (36) $18.6 \%$ & $(1.88 \pm .694)$ \\
\hline
\end{tabular}


Table 4: Coping strategies

\begin{tabular}{lllll}
\hline Variable & $\begin{array}{l}\text { Disagree } \\
(f) \%\end{array}$ & $\begin{array}{l}\text { Partially Agree } \\
(f) \%\end{array}$ & $\begin{array}{l}\text { Fully Agree } \\
(f) \%\end{array}$ & Mean \& St. Dv \\
\hline Self-confident approach & $(59) 30.4 \%$ & $(96) 49.5 \%$ & $(39) 20.1 \%$ & $(1.90 \pm .705)$ \\
Helpless approach & $(61) 31.4 \%$ & $(91) 46.9 \%$ & $(42) 21.6 \%$ & $(1.90 \pm .724)$ \\
Optimistic approach & $(57) 29.4 \%$ & $(85) 43.8 \%$ & $(52) 26.8 \%$ & $(1.97 \pm .751)$ \\
Yielding approach & $(0) 0 \%$ & $(94) 48.4 \%$ & $(100) 51.5 \%$ & $(2.52 \pm .501)$ \\
Social support seeking approach. & $(0) 0 \%$ & $(89) 45.9 \%$ & $(105) 54.1 \%$ & $(2.54 \pm .500)$ \\
\hline
\end{tabular}

Table 5: ANOVA

\begin{tabular}{|l|l|l|l|l|l|}
\hline & Sum of Squares & Df & Mean Square & F & Sig. \\
\hline Between Groups & 1.911 & 2 & .955 & 10.070 & .000 \\
Within Groups & 54.928 & 579 & .095 & & \\
Total & 56.838 & 581 & & & \\
\hline
\end{tabular}

The mean difference is significant at the 0.05 level.

Tukey HSD

\begin{tabular}{|c|c|c|c|c|c|c|}
\hline \multirow[t]{2}{*}{ (I) categories } & \multirow[t]{2}{*}{ (J) categories } & \multirow[t]{2}{*}{ Mean Difference (I-J) } & \multirow[t]{2}{*}{ Std. Error } & \multirow[t]{2}{*}{ Sig. } & \multicolumn{2}{|c|}{ 95\% Confidence Interval } \\
\hline & & & & & Lower Bound & Upper Bound \\
\hline \multirow[t]{2}{*}{ Academic stress } & clinical stress & .031 & .031 & .584 & -.04 & .10 \\
\hline & coping strategies & $-.103^{*}$ & .031 & .003 & -.18 & -.03 \\
\hline \multirow[t]{2}{*}{ clinical stress } & Academic stress & -.031 & .031 & .584 & -.10 & .04 \\
\hline & coping strategies & $-.134^{*}$ & .031 & .000 & -.21 & -.06 \\
\hline \multirow[t]{2}{*}{ coping strategies } & Academic stress & $.103^{*}$ & .031 & .003 & .03 & .18 \\
\hline & clinical stress & $.134^{*}$ & .031 & .000 & .06 & .21 \\
\hline
\end{tabular}

\section{Coping Strategies}

Data shown in Table 4 shows the coping strategies of respondents. Self-confident approach 30.4\% (n=59) participants were disagree, $49.5 \%(n=96)$ were agree, $20.1 \% \quad(n=39)$ were partially agree with $(1.90+.705)$. Helpless approach $31.4 \% \quad(n=61)$ participants were disagree, $46.9 \%(n=91)$ were agree, $21.6 \%(n=42)$ were partially agree with (1.90+.724).Optimistic approach $29.4 \%$ $(\mathrm{n}=57)$ participants were disagree, $43.8 \% \quad(\mathrm{n}=85)$ were agree, $26.8 \%(n=52)$ were partially agree with $(1.97+.751)$.

The mean difference is significant at the 0.05 level. Showed that to determine whether any of the differences between the means are statistically significant, compare the p-value to significance level. It is observed that academic and clinical stress sources and coping mechanisms are statistically significant, as p-value $<0.05$ (Table 5).

\section{Discussion}

The present study assesses the coping mechanisms of nursing students against academic and clinical stress in their academic and clinical placement in tertiary hospital of Lahore and was found that nursing students generally had moderate levels of academic and clinical practice stress.
The current study found that nursing students had multiple sources of academic and clinical stress. They experienced academic stressors such as preparing for exams, receiving negative feedback from teachers in the clinical environment, passing theoretical exams or assessments, not being satisfied with instructional methods, uncertainty about content and curriculum, gaps between theory and practice and lack of guidance from teachers. Most of the student is not being satisfied with instructional methods with mean (1.86+.768). In previous study among the clinical stressors, the highest number were given to being criticized by teachers in clinical environments followed by encountering a dying patient, the fear of making practice errors, not knowing how to help patients with emotional problems, not knowing how to help families of patients with emotional needs and not having enough time to provide emotional support to patients (Khater, Akhu-Zaheya, \& Shaban, 2014). In current study lack of guidance from teachers with mean and SD $(2.25 \underline{+} .768)$, insufficient support from teacher with mean and SD (2.20+.710), Passing theoretical exam or assessment with Mean and SD (2.25 .768),Intensity of academic workload with mean and SD (2.03 \pm .768$)$, Preparing for the exam with mean and SD 
(2.04_.797), Inadequately equipped classroom environment with mean and SD $(2.13+.797)$, Uncertainty about content and of curriculum with mean and SD (2.18+.743), Receiving negative feedback from teachers in clinical environment with mean and SD (2.03 \pm .737), Feelings of time pressure about doing homework with Mean and SD (1.94 \pm .749), Being forced to study continuously for academic success with mean and SD (1.96+.804), Being not satisfied with instructional methods with mean and SD (1.86+.768). On another hand in previous study the most common type of stressors perceived was stress from assignment work $(\mathrm{M}=2.12, \mathrm{SD}=0.88)$, followed by stress of peers and daily life $(\mathrm{M}=1.65, \mathrm{SD}=0.91)$ and from nursing staff and teachers $(\mathrm{M}=1.58, \mathrm{SD}=0.89)$. The major stress event students experienced was worrying about grades $(\mathrm{M}=$ $2.62, \mathrm{SD}=1.34$ ), followed by experiencing pressure from the nature and quality of clinical practice $(\mathrm{M}=2.15, \mathrm{SD}=1.22)$ and feeling that one's performance does not meet teachers' expectations $(\mathrm{M}=1.98, \mathrm{SD}=1.17)$. Minor stress the students experienced was related to communication with patients $(\mathrm{M}=.85 ; \mathrm{SD}=1.14)$, inability to provide patients with good nursing care $(\mathrm{M}=1.18 ; \mathrm{SD}=1.07)$, and being unfamiliar with medical history and terms $(\mathrm{M}=1.25 ; \mathrm{SD}=1.09)$ (Chan et al., 2014). In current study most of the student used coping strategies are Self-confident approach are used with

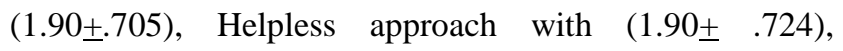
Optimistic approach used with $(1.97 \pm .751)$, Yielding approach used with $(2.52 \pm .501)$, Social support seeking approach used with mean $(2.54 \pm .500)$. In previous study coping strategies used most of the student are Seeking diversions (22.55 \pm 3.722$)$, Self-reliance (19.69 \pm 4.38$)$, Developing social support (18.84 \pm 3.72$)$, Solving family problems (18.14 \pm 4.17$)$, Ventilating feelings (14.84 \pm 3.13$)$, engaging in demanding activities (13.04 \pm 3.435$)$, Relaxing (11.47 \pm 2.58$)$, Avoiding (11.29 \pm 4.036$)$, seeking spiritual support $(6.71 \pm 1.91)$, being humorous (6.69 \pm 2.083$)$, investing in close friends $(6.35 \pm 2.30)$, seeking professional

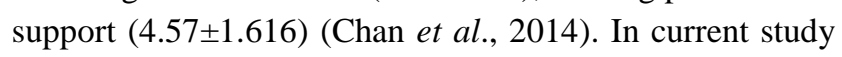
ANOVA test is used to test mean differences of clinical and academic stress and coping strategies of student, there is significance association between clinical and academic stress with $\mathrm{p}$ value<.05 and mean difference value 955.There is a significance association between academic and clinical stress and coping strategies. ANOVA test was used to test mean differences of clinical and academic stress resources and coping strategies in students of different academic years. The results revealed that the student's academic year was directly associated with the student's stress level $(\mathrm{F}=8.34$; df = 2, 594, $\mathrm{p}<.05)$. Further analysis with Bonferroni post-hoc test showed that students used coping strategies to cope with clinical and academic strategies are strongly associated with $\mathrm{p}$ value <.05of student (Jameson, 2014).

\section{Conclusion}

In summary, the academic and clinical practice stress levels of nursing students were moderate in their academic and clinical placement. Most of the students were found to use self-confident, optimistic approaches and social support seeking approaches among coping strategies. The Clinical instructor helps students to cope with challenges related to nursing education and increases their academic success. Therefore, it is suggested that academic and clinical teacher should be used coping strategies to decrease their nursing students academic and clinical stress levels and to increase their positive coping strategies in nursing schools and at clinical placement. Additionally, nursing students had both academic and clinical sources of stress. The responsibility of instructors in academic and clinical environments is to decrease the stress levels and sources of stress for students, to assist students in providing and maintaining psychosocial adaptation, and to empower students' learning in bridging the theory-practice gap.

\section{Strength of the study}

The present study has a number of strength which is as follow:

1) This is a first study conducted in Tertiary Hospital of Lahore Pakistani context which assessed the coping strategies of nursing student against clinical and academic and clinical stress resources.

2) In this study the questioner tool was used, which was already been tested for validity and reliability.

3) The large sample size i.e., 194 in this study also enhanced the internal validity of the research.

4) Data collected in the supervision and accurate information was collected.

\section{Limitation}

The study has certain limitations that need to be acknowledged in the interpretation of the result.

1) This is a cross-sectional study, therefore inferences related to the causality of association could not be draw, however, case control and cohort studies should be conducted to establish causal relationship.

2) As the data is collected from only one setting, it has limited generalizability.

3) Convenient sampling was applied in data collection process whereas the probability sampling method can enhance the induction of different strata of the participants.

4) The study is limited to assess the coping strategies of nursing student against academic and clinical stress resources. 


\section{Recommendation}

Based on the study results, the following strategies are recommended in order to develop coping strategies among nursing student against clinical and academic stress through:

- Hospital leaders should plan and implement effective coping strategies against clinical and academic stress to promote nursing student.

- Creating a more supportive professional nursing practice that allows nursing student to practice to their full opportunities for professional interactions. This can be done through the development of a clinical ladder for advancement within the organization.

- Motivating nursing student through developing reward systems for nursing student based on their workloads and performance.

- Improving the image of nursing profession through effective marketing, good media, as well as emphasizing the actual role of mercy angels.

- Creating opportunities to attract nursing student by strengthening the interpersonal communication and management skills within the academic and clinical placement.

- Enhancing a positive work environment through promotion of teamwork, encouraging continuous education, trust, respect and flexible scheduling.

\section{References}

Acikgoz C, Sahbaz DA and Balbay S (2016). Determination of anionic surfactant adsorption capacity of expanded perlite from aqueous solution. FebFresenius Environmental Bulletin: 3447.

Akhu-Zaheya LM, Shaban IA and Khate WA (2015). Nursing students' perceived stress and influences in clinical performance. International Journal of Advanced Nursing Studies 4(2): 44.

Allan CL, Sexton CE, Filippini N, Topiwala A, Mahmood A, Zsoldos E, Singh-Manoux A, Shipley MJ, Kivimaki M, Mackay CE, Ebmeier KP (2016) Subthreshold depressive symptoms and brain structure: A magnetic resonance imaging study within the Whitehall II cohort. Journal of affective disorders 204: 219-225.

Badil B, Shah H, Ali SA, Siddiqui A (2016). Occupational Stress among Nurses of Tertiary Care Hospitals in Karachi, Pakistan. Journal of Dow University of Health Sciences 10(3): 730-740.

Bahadır-Y1lmaz E (2016) Academic and clinical stress, stress resources and ways of coping among Turkish first-year nursing students in their first clinical practice. Kontakt 18(3): e145-e151.
Blomberg G, Sherin MG, Renkl A, Glogger I and Seidel T (2014) Understanding video as a tool for teacher education: investigating instructional strategies to promote reflection. Instructional Science 42(3): 443 463.

Bryan ML, Knutson HA, Howard AW, Ngo H, Batygin K, Crepp JR, Fulton BJ, Hinkley S, Isaacson H, Johnson JA, Marcy GW (2016) Statistics of Long Period Gas Giant Planets in Known Planetary Systems. The Astrophysical Journal 821(2): 89.

Chan ZC, Chan YT, Lui CW, Yu HZ et al. (2014) Gender differences in the academic and clinical performances of undergraduate nursing students: A systematic review. Nurse education today 34(3): 377-388.

Demir E, Bektaş T and Laporte G (2014) A review of recent research on green road freight transportation. European Journal of Operational Research 237(3): 775-793.

Forouzanfar MH, Afshin A, Alexander LT, Anderson HR, Bhutta ZA, Biryukov S, Brauer M, Burnett R, Cercy K, Charlson FJ, Cohen AJ. (2016). Global, regional, and national comparative risk assessment of 79 behavioural, environmental and occupational, and metabolic risks or clusters of risks in 188 countries, 1990-2013: a systematic analysis for the Global Burden of Disease Study 2015. The Lancet 388(10053):1659-1724.

Furukawa S, Fujita T, Shimabukuro M, Iwaki M, Yamada Y, Nakajima Y, Nakayama O, Makishima M, Matsuda M and Shimomura I (2017) Increased oxidative stress in obesity and its impact on metabolic syndrome. The Journal of clinical investigation 114(12): 1752-1761.

Hawker CL (2012) Physical activity and mental well-being in student nurses. Nurse education today 32(3): 325 331.

Huber D, Chaplin WJ, Christensen-Dalsgaard J, Gilliland RL, Kjeldsen H, Buchhave LA, Fischer DA, Lissauer JJ, Rowe JF, Sanchis-Ojeda R and Basu S (2013) Fundamental properties of Kepler planetcandidate host stars using asteroseismology. The Astrophysical Journal 767(2): 127.

Jameson PR (2014) The effects of a hardiness educational intervention on hardiness and perceived stress of junior baccalaureate nursing students. Nurse education today 34(4): 603-607.

Jung YK and Park HG (2015) Colorimetric detection of clinical DNA samples using an intercalatorconjugated polydiacetylene sensor. Biosensors and Bioelectronics 72: 127-132. 
Khater, W., Akhu-Zaheya, L., \& Shaban, I. (2014). Sources of stress and coping behaviours in clinical practice among baccalaureate nursing students. International Journal of Humanities and Social Science, 4(6), 194202.

Knutson, H. A., et al. (2014). "Friends of hot Jupiters. I. A radial velocity search for massive, long-period companions to close-in gas giant planets." The Astrophysical Journal 785(2): 126.

Lazarus, R. S., \& Folkman, S. (1984). Coping and adaptation. The handbook of behavioral medicine, 282-325.

Liu M, Gu K, Wong TK, Luo MZ, Chan MY. (2015) Perceived stress among Macao nursing students in the clinical learning environment. International Journal of Nursing Sciences 2(2): 128-133.

Malig BJ, Pearson DL, Chang YB, Broadwin R, Basu R, Green RS, Ostro B (2016) A time-stratified casecrossover study of ambient ozone exposure and emergency department visits for specific depression diagnoses in California (2005-2008). Environmental health perspectives 124(6): 745.

Milsom I, Kaplan SA, Coyne KS, Sexton CC, Kopp ZS (2012) Effect of bothersome overactive bladder symptoms on health-related quality of life, anxiety, depression, and treatment seeking in the United States: results from epiluts. Urology 80(1): 90-96.

Papathanasiou IV, Tsaras K, Sarafis P (2014). Views and perceptions of nursing students on their clinical learning environment: Teaching and learning. Nurse education today 34(1): 57-60.
Rinsky JL, Nadimpalli M, Wing S, Hall D, Baron D, Price LB, Larsen J, Stegger M, Stewart J, Heaney CD (2013). Livestock-associated methicillin and multidrug resistant Staphylococcus aureus is present among industrial, not antibiotic-free livestock operation workers in North Carolina. Plos one 8(7): e67641.

Roberts RK and Grubb PL (2014) The consequences of nursing stress and need for integrated solutions. Rehabilitation Nursing 39(2): 62-69.

Sikander S and Aziz F (2012) Stressors and Coping Strategies among Baccalaureate Nursing Students at Shifa College of Nursing Islamabad, Pakistan. International Journal of Nursing Education 4(2).

Thompson B (1993) The use of statistical significance tests in research: Bootstrap and other alternatives. The Journal of Experimental Education 61(4): 361-377.

Torres G, Kipping DM, Fressin F, Caldwell DA, Twicken JD, Ballard S, Batalha NM, Bryson ST, Ciardi DR, Henze CE, Howell SB (2015) Validation of 12 small Kepler transiting planets in the habitable zone. The Astrophysical Journal 800(2): 99.

Van Eylen V, Lund MN, Aguirre VS, Arentoft T, Kjeldsen $\mathrm{H}$, Albrecht S, Chaplin WJ, Isaacson H, Pedersen MG, Jessen-Hansen J, Tingley B (2014) What asteroseismology can do for exoplanets: Kepler$410 \mathrm{~A} \mathrm{~b}$ is a small Neptune around a bright star, in an eccentric orbit consistent with low obliquity. The Astrophysical Journal 782(1): 14. 